\title{
Coastal economic vulnerability to sea level rise of Bohai Rim in China
}

\author{
Ting $\mathrm{Wu}^{1} \cdot$ Xiyong Hou ${ }^{1} \cdot$ Qing Chen ${ }^{1}$
}

Received: 18 August 2015/Accepted: 10 October 2015/Published online: 22 October 2015

(C) Springer Science+Business Media Dordrecht 2015

\begin{abstract}
Through index-based method, the coastal economic vulnerability of Bohai Rim in China to the hypothetical local scenario of $1-\mathrm{m}$ relative sea level rise by the end of twenty-first century was assessed (note that 1-m global sea level rise throughout the twenty-first century is highly improbable). Both physical and socioeconomic variables were considered, and the comparison between physical vulnerability and economic vulnerability was conducted to identify effects of socioeconomic variables on coastal susceptibility to sea level rise. The assessment was carried out at shoreline segments scale as well as at county-level scale, and the results were as follows: The combination of geomorphology and terrain plays the determinant role, since the gently sloped coasts with softer substances are always both physical and economic susceptible to the projected inundation scenario; potential displaced population and GDP loss have more influence on economic vulnerability than reclamation density in that the most intensively reclaimed areas are not always high vulnerable, while the areas that may suffer from the largest potential displaced population and GDP loss are always high vulnerable; the method employed in this study is sensitive in identifying the relative difference in economic vulnerability; moreover, it is capable of handling the issues caused by mutual offset effects between land-controlling impacts and marine-controlling impacts. The insights offered by this study could inform the coastal managers in optimizing allocation of limited resources and, consequentially, assist them to sequence policy, planning and management choices efficiently and effectively to adapt to the sea level rise.
\end{abstract}

Keywords Coastal economic vulnerability $\cdot$ Relative sea level rise $\cdot$ Shoreline $\cdot$ Bohai Rim · China

Xiyong Hou

xyhou@yic.ac.cn

1 Yantai Institute of Coastal Zone Research, Yantai, China 


\section{Introduction}

As the IPCC suggested, the most likely scenario of global sea level rise (SLR) for the end of the twenty-first century is $25 \mathrm{~cm}$; however, according to the Chinese Sea Level Bulletin of 2014, the relative sea level of Bohai in China was predicted to rise by $68-140 \mathrm{~mm}$ in the next 30 years, which had considered both the increase in the global sea level rise and the effect of the local tectonic processes in the area of Bohai Rim. Therefore, to make our conclusions more convincible and reasonable, we selected the intermediate value, $100 \mathrm{~mm}$, as our hypothetical SLR scenario of Bohai Rim for the end of twenty-first century to conduct our study. What has to be clarified is that the global scenario of $1 \mathrm{~m}$ SLR by the end of twenty-first century is highly improbable.

Based on the concept of vulnerability (Alpar 2009; Das 2012; Torresan et al. 2012; Jana and Bhattacharya 2013; Thatcher et al. 2013), the present study aimed at presenting relative differences in coastal vulnerability to sea level rise of Bohai Rim under the hypothetical scenario that the sea level of Bohai will rise by $1 \mathrm{~m}$ throughout the twenty-first century. In addition to the conventional six variables (geomorphology, regional coastal slope, shoreline change rate, relative sea level change rate, mean wave height, and mean tide range; Dwarakish et al. 2009; Wang et al. 2013), population, GDP, and reclamation density in potential inundated area of each county were considered. This paper was also characterized by the facts that: The population raster data were obtained according to the relationship between the quantity of population and the magnitude of nighttime light; the coastline was segmented at places where any one of the nine variables changed; the potential inundated areas referred to the lands that were below a given elevation and directly connected to the ocean. The highlighted area with relative higher vulnerability could help the managers sequence the areas in planning protective measures and identify areas unsuitable for further development and utilization (Torresan et al. 2008).
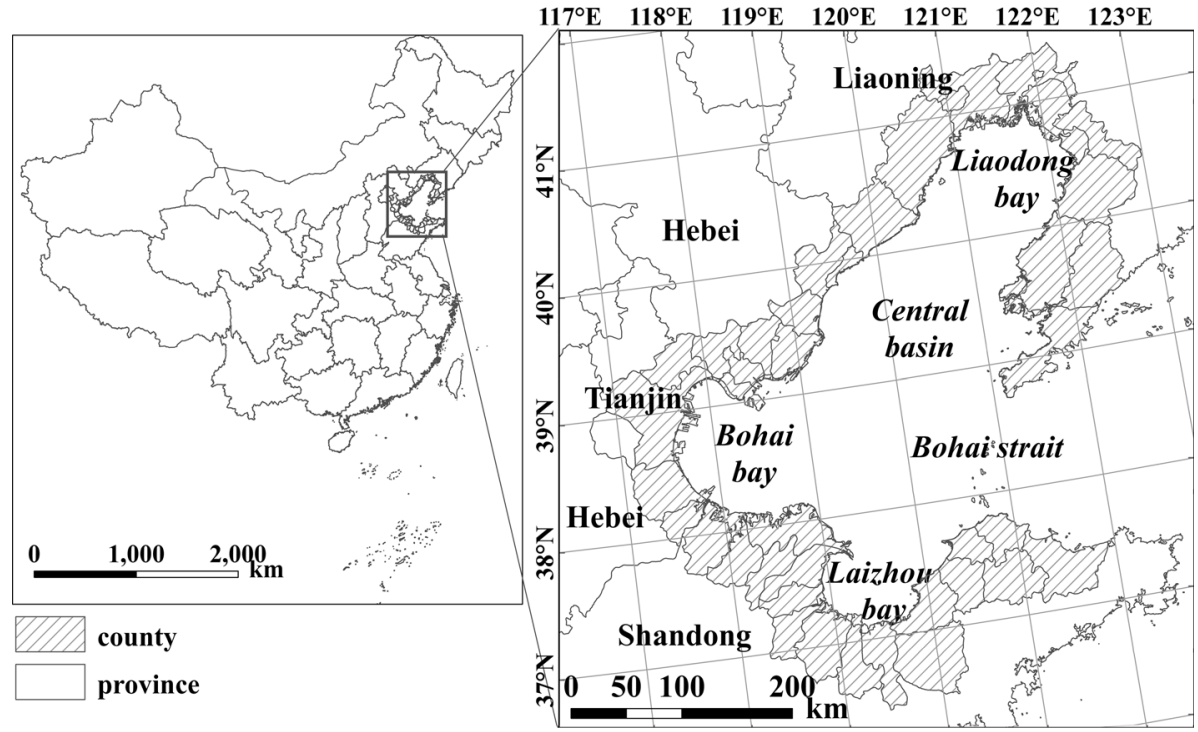

Fig. 1 The study area 


\section{Study area}

The Bohai sea, enclosed by Bohai Rim, is situated within $37^{\circ} 07^{\prime}-41^{\circ} \mathrm{N}$ and $17^{\circ} 35^{\prime}-$ $122^{\circ} 15^{\prime} \mathrm{E}$, covering a sea area of approximately $77,284 \mathrm{~km}^{2}$ (Wang et al. 2013), and is comprised of Liaodong Bay, Bohai Bay, Laizhou Bay, Central Basin, and Bohai Strait. Bohai Rim is located in the temperate zone and has a humid continental monsoon climate featuring four distinct seasons. There are various coastal typologies in this coastal area, and in terms of the composition of coastal materials, bedrock coast, gravel coast, silt-muddy coast, and muddy coast are dominant here (Wu et al. 2014). Several great rivers, such as the Liao River, the Luan River, the Hai River, the Yellow River, flow through this area and finally empty into the Bohai, contributing to the development of typical estuary geomorphologies (estuary delta, sandbank, sandbar, and sand spit) and the wide distribution of coastal wetlands.

Administratively, Bohai Rim belongs to Liaoning Province, Hebei Province, Shandong Province, and Tianjin Municipality. Only 42 counties that directly bordered the Bohai or located very near the sea border were selected to constitute our study area (Fig. 1). Thus, the Bohai Rim hereinafter in this paper merely refers to counties adjoining to Bohai coastline. This studied area had been the new engine of development in China. Since 2000, four economic zones at national level, the Tianjin Binhai New Area, the Liaoning Coastal Economic Zone, the Yellow River Delta Eco-economic zone, and the Blue Economic Zone of Shandong Peninsula, were implemented successively here, leading to more rapid population aggregation and more intensive expansion of city and industry. By 2010, the population had reached 34 million and the GDP had approximately amounted to 2.9 trillion RMB with a per capita value of 84,587 yuan a year.

\section{Data and methodology}

\subsection{Data source and data processing}

The preferable way to evaluate coastal vulnerability is based on coastal vulnerability index (CVI) first proposed by Gornitzt (1991). Its numeric expressions may be the square root of the geometric mean of the ranking factors or the sum of differentially weighted variables. Studies (Haer et al. 2013; Thatcher et al. 2013) indicate that the later one (Eq. 1) is more effective in expressing the spatial variations of coastal vulnerability:

$$
\mathrm{CVI}=\sum_{i}^{n} P_{i} C_{i}
$$

where CVI is the coastal vulnerability index, $P_{i}$ is the score the $i$ th variable gets, $C_{i}$ is the weight assigned to the $i$ th variable, $n$ is the number of variables. The greater the CVI, the more vulnerable the coast to sea level rise. Generally, equal weight was assigned to the variables, implicating that all the variables have an equal importance in determining the vulnerability.

In addition to the conventional six variables, viz., geomorphology, regional coastal slope, shoreline change rate, relative sea level change rate, mean wave height, and mean tide range, population, GDP, and reclamation density in potential inundated area were involved to evaluate the economic coastal vulnerability of Bohai Rim. The index that considered economic factors was termed economic coastal vulnerability index (ECVI). 
Geomorphology indicates the resistance of coast to SLR-induced erosion. National Geomorphology Map exploited in this study was downloaded from the Data-Sharing Network of Earth System Science (http://www.geodata.cn/Portal/index/).

Regional coastal slope indicates the susceptibility of the coast to SLR-induced inundation. It was derived from the 1-arc-second (about $30 \mathrm{~m}$ ) Advanced Spaceborne Thermal Emission and Reflection Radiometer (ASTER) Global Digital Elevation Model (GDEM) V2 downloaded for free from USGS website (http://gdex.cr.usgs.gov/gdex/).

Shoreline change rate indicates the degree to which the coastline has changed. In this study, 6 shorelines of Bohai Rim in 1940s, 1960s, 1990, 2000, 2010, 2012 were extracted from topographic maps of 1940s and 1960s, charts of 1960s, remote sensing imageries of 1990, 2000, 2010 and 2012. Shoreline change rate, then, was calculated through the method of linear regression based on transects cast perpendicularly to the general orientation of all shorelines.

Relative sea level change rate states the increase in the local sea level and the effect of the local tectonic processes on the stretch of coastline. The average relative sea level change rates at provincial and municipal level since the twenty-first century were sourced from the Chinese Sea Level Bulletin.

Mean wave height is a proxy for wave energy which drives the coastal sediment budget; mean tide range contributes to the inundation hazards. These two kinds of data were collected from tide gauge stations, historical documents, or previous studies.

Population and GDP in potential inundated area are the displaced population and the economic loss that would occur in the face of SLR-induced inundation, respectively. Statistics of population at county level were obtained by the Sixth Nationwide Census in 2010. To acquire a continuous population surface, we redistributed population to a $900-\mathrm{m}-$ resolution raster dataset based on the 900-m-resolution nighttime light raster dataset on the assumption that population was directly proportional to the light intensity. Afterward, potentially displaced population was extracted by the potential inundated area polygon and was added up by county. Since the Nationwide Census was conducted at a 5-year interval, there was a lack of population data in 2012, and as a result, we compromised by setting the loss of GDP at county scale as the product of displaced population and GDP per capita in 2010 instead of in 2012. The GDP per capita data at county level were collected from the statistical yearbook.

Reclamation density in inundated area of each county represents the degree to which reclamation weakens the resistance of coast to inundation or attenuates the self-adjustment capacity of coast in the occurrence of inundation. Reclamation projects invade or spoil wetlands which can hinder the flood water from propagating further inland through its adaptive mechanism (Kirwan and Megonigal 2013; Reed 1995). Additionally, reclamation projects diminish the drainage capacity of coastal soil resulting in the retention of the flooding water which would exacerbate the inundation situation. Polygons developed from the intersection performance of the 1940s shoreline and the 2012 shoreline were confirmed by referencing literatures, and consequentially, the ultimate reclamation polygon data were obtained. Reclamation density was characterized as reclamation area in each of the $10 \mathrm{~km} \times 10 \mathrm{~km}$ grids covering the whole coastline.

Scores of each variable were standardized to the scale of $0-1$, with 0 represented the least vulnerable and 1 represented the most vulnerable (Gesch 2009):

$$
X_{i}=\frac{R_{i}-R_{\min }}{R_{\max }-R_{\min }}
$$


where $R_{i}$ is the score of the $i$ th variable within one unit, $R_{\min }$ is the minimum score of the $i$ th variable among all units, $R_{\max }$ is the maximum score of the $i$ th variable among all units.

\subsection{Methodology}

For lack of professional models for the simulation of flood propagation, the potential inundated zones, referencing to the preferable processing method the world over, are simply defined as the regions that have an elevation at or below a given sea level rise scenario and are hydrologically connected to the ocean on the basis of GDEM (Gesch 2009). Such connectivity of neighboring cells could be identified by being adjacent to the ocean or inundated cells on any the cardinal directions (4-way connectivity) or by being adjacent on any of the cardinal or diagonal directions (8-way connectivity) (Poulter and Halpin 2008).

The extremely unlikely hypothetical scenario of $1 \mathrm{~m} \mathrm{SLR}$ by the end of the twenty-first century was considered as a worst-case scenario and was used in this study. This hypothetical scenario was within the statistical uncertainty of the GDEM based on the error assessment below. As coastal topography and the given scenario both played an critical role in the vulnerability assessment, the vertical accuracy of the GDEM within the study area should be explicitly factored into depicting the spatial extent of potential inundated area (Thatcher et al. 2013). The vertical accuracy was calculated by comparison with an independent set of uniformly distributed control points from Google Earth and was expressed by the root-mean-square (RMSE; Gesch 2009):

$$
\mathrm{RMSE}=\operatorname{sqrt}\left[\sum\left(Z_{\mathrm{data} I}-Z_{\text {checkI }}\right)^{2} / n\right]
$$

where $Z_{\mathrm{data}}$ is the vertical coordinate of the $I$ th check point in GDEM, $Z_{\text {check } I}$ is the vertical coordinate of the Ith check point in Google Earth, $n$, the number of points being checked, is 645 in this study, and $I$ is an integer from 1 to $n$. This metric turned out to be 7.2 in this study. The linear error at a $95 \%$ confidence level, a metric used by the National Standard for Spatial Data Accuracy (NSSDA) (Federal Geographic Data Committee 1998), was $14.112 \mathrm{~m}$, as calculated by multiplying the RMSE by 1.96 (Thatcher et al. 2013). This error was in high accordance with the result Zhang et al. obtained in 2014 for Eastern China by comparing GDEM with the DEM at 1:50,000 scale.

The spatial extent of the inundated area was calculated a second time by adding $14.112 \mathrm{~m}$ to the $1-\mathrm{m}$ relative sea level rise (worst-case scenario), and more area representing the spatial uncertainty was acquired. The 14.112 confidence interval for 1-m relative sea level rise (worst-case scenario) is not acceptable when aiming at producing accurate and reliable maps of potential inundation zones, such that, we shifted our attentions to relative disparities in vulnerability of lands to relative sea level rise.

The analysis unit in this study referred to shoreline segments. Coastline of Bohai Rim was segmented at points where any of variables changed, resulting in homogeneous vulnerable shoreline segments for each target of interest. To start, the six conventional variables were concerned alone to calculate the physical coastal vulnerability; economic coastal vulnerability (ECVI) incorporating all the physical variables and variables of population; and GDP in inundated area followed; furthermore, economic coastal vulnerability (ECVII) incorporating all variables aforementioned was calculated to analyze the role reclamation density played in the vulnerability assessment; additionally, economic coastal vulnerability that incorporate all the nine variables was then averaged by county 
(ECVC) to identify the most vulnerable counties to relative sea level rise, which would assist the managers to make better-informed decisions at county level.

\section{Results}

Maps of physical coastal vulnerability (PCV), economic coastal vulnerability, ECVI, ECVII, and ECVC, were obtained by dividing the vulnerability index into very low-, low-, moderate-, high-, and very high vulnerability categories by quintile classification method, respectively (Figs. 2, 3).

The score of physical coastal vulnerability ranges from 1.20 to 5.25, with an average of 3.13 and a standard deviation of 0.75 . Though the eastern coast of Liaodong Bay is homogeneously low or very low physical vulnerable, the control factors vary with coastal conditions. The coast south of Fuzhou Bay is prevailed by bedrock, and the typical geomorphology of rocky coast-steep terrain and hard substrates-provides a strong resistance to SLR-induced erosion, making the coastline remain stable. Instead, the relative low vulnerability of its northern part is primarily attributed to the secure marine dynamic conditions, since the lowest mean wave height and the largest mean tidal range ensure the coast holding the lowest possibility of being inundated. The Binhai New Area of Tianjin presents low physical vulnerability for its secure marine dynamic conditions, and Huanghua City of Hebei Province exhibits very low physical vulnerability for the combination of its stable shoreline, larger mean tidal range and slow relative sea level rise. The coast in Shandong Province is dominated by high or very high vulnerability, since the terrain slopes gently, the substrates are easily erosive, the sea adjacent to this area has the most powerful dynamic, and velocity at which relative sea level rises is the fastest. Despite having the identical marine dynamic, similar relative sea level rise rate, and coastal geomorphology, the south coast of Laizhou Bay is less vulnerable than the rest coasts belong to Shandong Province due to its stable shoreline resulting from lagging and patterned coastal development.

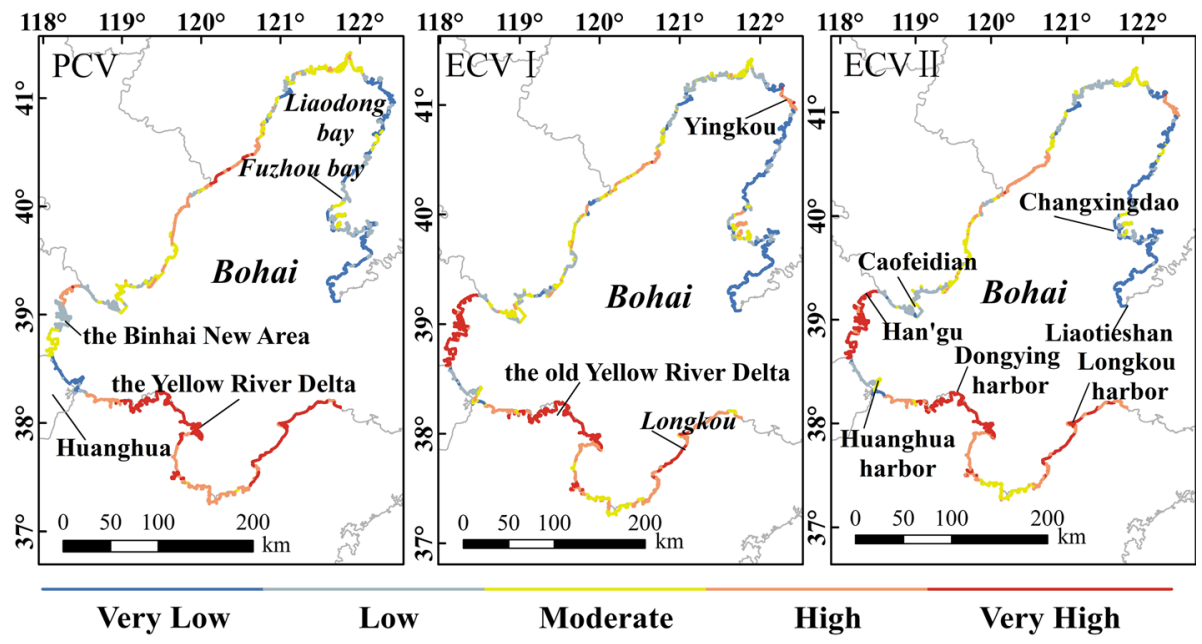

Fig. 2 Maps of PCV, ECVI, ECVII 
Fig. 3 Map of ECVC

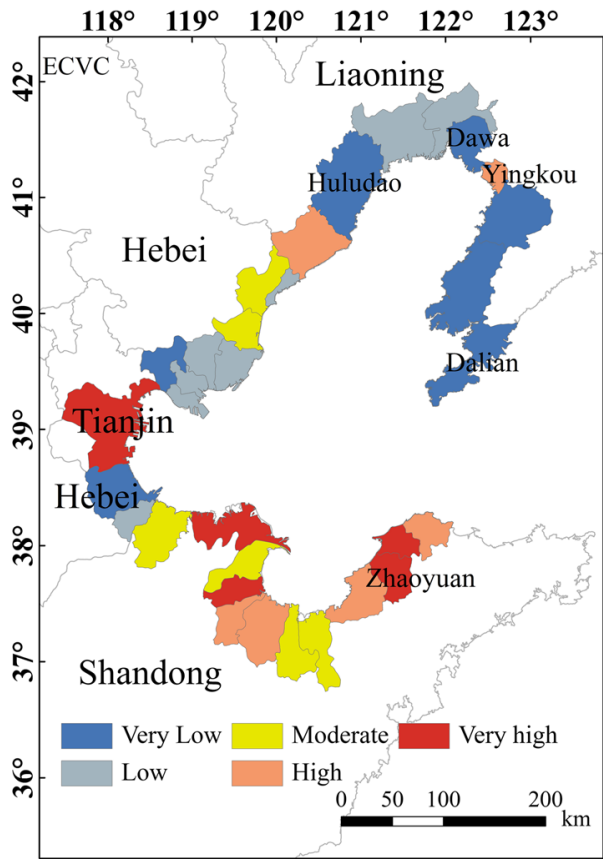

The score of ECVI ranges from 1.36 to 5.70, with an average of 3.37 and a standard deviation of 0.81 . Most of the eastern coasts of Liaodong Bay, except for Yingkou which may suffer the largest displaced population and GPS loss in the face of projected SLRinduced inundation, remain low economic vulnerable. The coast of Tianjin, where harbor and harbor industry are prevailing, turns to be very high economic vulnerable due to the heaviest potential GPS loss. Though the old and current Yellow River Delta and the coast of Longkou Bay would suffer the least displaced population and GPS loss due to the underdeveloped economy and sparse population distribution, those areas remain high economic vulnerable because of their high physical vulnerability.

When incorporating reclamation density, the ECVII ranges from 1.36 to 5.70, with an average of 3.54 and a standard deviation of 0.82 . The spatial distribution of vulnerability is similar to ECVI; however, some discrepancies do occur; for instance, Changxingdao witnesses a general aggravation of vulnerability because of the island-mainland link project, and Caofeidian undergoes a slight aggravation of vulnerability due to the reclamation for industry. Being identical to ECVII, the least economic vulnerability is observed at Laotieshan which can be attributable to its lowest physical vulnerability, and the highest economic vulnerability occurs at Han'gu district of Tianjin due to the largest potential GDP loss with a moderate population at risk.

The similarity between the spatial distribution of ECVI and ECVII denotes that the population and GDP in potential inundated area are positively correlated with reclamation density, which has a reasonable explanation in practical life-larger population and more intensive economic activities need more lands for relieving the land pressures, and in reverse, more lands would attract more people and more economic activities. However, reclamation density could not be excluded when analyzing the economic coastal vulnerability in that it contributes to the economic vulnerability conversion from low to high of 
the coasts which might witness a small-scale potential population displacement and GDP loss but a high intensive reclamation. Therefore, we analyzed the economic vulnerability on county level based on ECVII.

The counties on Liaodong Peninsular and Huludao Municipality exhibit very low economic vulnerability. The reason lies in the high relief and the hard substrates that combine to play a key role in resisting to the SLR-induced erosion and inundation. In particular, Dalian holds the lowest economic vulnerability, in spite of being productive and extensively reclaimed. Dawa county, lying on Liaohe alluvial plain and such that being low-relief and softer area, presents very low economic vulnerability as well, which could be attributed to the sparse population and underdeveloped economy. Furthermore, Hebei Province is generally low economic vulnerable in that the slowest relative sea level rise, slow-speed coastline development and low-level coastline utilization synthetically result in the small potential displaced population and GDP loss.

Low-relief coastal counties with softer substrates, accompanied by higher relative sea level rise and wicked ocean dynamic condition, generally exhibit higher economic vulnerability, like the counties in Shandong Province. The highest economic vulnerability occurs at Tianjin. The combination of its gently sloped terrain and relative sea level rising faster leads to Tianjin high physical vulnerable to SLR-induced inundation; in addition, as harbors and harbor industry are prevalent, this coastal area is most productive with relatively larger population; thus, it is projected to witness the greatest GDP loss and a larger displaced population in the context of 1-m relative sea level rise scenario. The physical vulnerability of Yingkou is similar to its surrounding counties; however, the economic vulnerability is significantly distinguishable, as it is expected to suffer the maximum inundated area which would lead to a relative larger population displacement and GDP loss.

\section{Discussion}

Geomorphology, coastal slope, relative sea level rise rate, and mean tidal range play a vital importance in both physical and economic vulnerability assessment, especially geomorphology and coastal slope. The very low physical vulnerable coast which has a strong resistance to SLR-induced erosion and a high gradient remains very low economic vulnerable, like the bed-rocky coasts of Liaoning Province; the very high physical vulnerable coast which is highly susceptible to SLR-induced erosion and sloped gently remains very high economic vulnerable, like the muddy coast - the Yellow River Delta.

The downdrift coast of harbors is always high vulnerable whether from the physical perspective or from the economic perspective. The fact that groins and jetties of harbors would break the alongshore current (Saranathan et al. 2011) can account for this phenomenon: the sediments carried by the alongshore current all get captured on the updrift side, such that accumulation downdrift is hindered (Allersma and Tilmans 1993), consequently, the erosion problem shifts downdrift or the ongoing erosion issues of downdrift area deteriorates.

Incorporating the economic factors expands the spatial discrepancy of vulnerability, refining the highlighted area. The spatial variation of the differences between the physical vulnerability and the economic vulnerability indicated that reclamation density had less effect on the economic coastal vulnerability in that the differences are moderate in the most intensively reclaimed areas and yet are the biggest in the areas that hold the largest 
potential displaced population and GDP loss. And the biggest differences occur at Yingkou municipal district of Liaoning Province for holding the largest potential displaced population and GDP loss, and at the Tianjin Binhai New Area for holding the largest GDP loss though a moderate potential displaced population.

Low-relief and softer coast with productive industry like Tianjin always has a very high economic vulnerability. Stable coast whether the stability is attributed to firm geomorphology or low-level utilization refers to lower economic vulnerability, like Dalian where the gradient terrain and the hard substrates lead to it being lower vulnerable, and also like Huanghua and south coast of Laizhou Bay, where onefold and low-level exploitation for aquaculture and salt pan leads to them staying stable and make them lower vulnerable than the coasts with similar physical control factors. Judging from that, the index proposed in the paper is sensitive and effective in detecting the economic vulnerability.

Yingkou municipal district of Liaoning Province is in a relative secure marine dynamic conditions, and the shoreline stays stable owing to the low-level utilization; therefore, its physical vulnerability is low; however, its gently sloped terrain, softer substrates, and the high relative sea level rise rate are expected to lead this place to suffer the most extensive inundation area which will result in the largest displaced population and GDP loss. That is why Yingkou is less developed but has a high economic vulnerability. In view of that, economic vulnerability index could identify the coast where the effects of land conditions and marine conditions on physical vulnerability are mutual offset, and above all, the issue that the coast which should have had a high vulnerability exhibits a low vulnerability caused by that kind of offset can be eliminated. The equal weight of variables is a disadvantage of this study since different variables have unequal importance in the vulnerability assessment. However, the subjective weighting of variables, currently, still has limitations; therefore, more generally arguable weighting method deserves further attentions. The lack of high-resolution population raster data and highly accurate DEM is the main restriction of this study to produce accurate and reliable maps of potential displaced population and inundation zones. Thus, we targeted identifying the highlighted areas (very high vulnerable or very low vulnerable places) and the main influencing factors instead of the accurate risk maps. Additionally, the economic vulnerability analysis was based on the current population, GDP, and reclamation conditions that did not concern their future trend. Hence, this study may underestimate the potential displaced population, GDP loss, and the importance of reclamation density.

\section{Conclusions}

Under a highly improbable hypothetical worst-case scenario of 1-m sea level rise, this study conducted the physical coastal vulnerability assessment based on the conventional six physical variables, and the economic coastal vulnerability assessment by incorporating potential displaced population, GDP loss, and reclamation density, respectively, for the coast of Bohai Rim. The results exhibit that: (1) The gently sloped and muddy or sandy coasts are always not only physical susceptible but also economic susceptible to the projected inundation scenario, like the Yellow River Delta; (2) potential displaced population and GDP loss have more significant influence than reclamation in the economic vulnerability assessment, while the influences of geomorphology, coastal slope, mean tidal range, and relative sea level rise are more significant than the other two physical variables; and (3) the method employed in this study for economic vulnerability assessment is 
sensitive and preferable, not only because it is capable of identifying the relative difference in economic vulnerability but also because it performs competently in handling the issues resulted from offset process of land-controlling impacts and marine-controlling impacts.

The vulnerability assessment of this study was performed at both shoreline segments level and county level; therefore, the method could assist the coastal managers make better-informed decisions in coastal development and utilization at local and county scale, respectively. These highlighted areas, pointing out the most vulnerable areas, thus, should be given the top funding priority to reduce risk. Specific remedial or preventative measures include: to construct coastal protection project, to establish nature reserve to protect or restore coastal ecosystem, to migrate coastal population or industries to protect life and property's safety.

It is apparent that inundation may bring a range of other consequences, for instance the cost of insuring property, the intrusion of saltwater into groundwater, the inundation of roads and municipal infrastructure, the presence of hazardous waste along the coast (Crowell et al. 2010; Arkema et al. 2013). Therefore, compared to the physical impacts, the potential socioeconomic impacts of relative sea level rise throughout the twenty-first century carry more weight with the authorities; thus, the deep insights into them offered by the economic vulnerability would heighten the managers' risking awareness to relative sea level rise, spurring them to take proactive measures to prevent the imminent coastal hazardous. The values of economic vulnerability allow for a comparison between counties and local regions in terms of land inundation, population at risk and GDP affected, based on which, coastal managers could work to optimize allocation of limited manpower, material and financial resources and, consequentially, implement and sequence policy, planning and management choices efficiently and effectively to adapt to the impacts of relative sea level rise.

Limitations of the present study have been noted in the discussion paragraphs. In the following study, employment of more accurate elevation data and population density raster should be a priority. Furthermore, more detailed analysis of the potential economic and social coasts of SLR-induced inundation is warranted to identify particularly vulnerable localities. Additionally, assessment based on unequally weighted variables deserves attempt and the weights should be determined by the stakeholders and the experts such that conduction of survey and interview is required.

Acknowledgments This research was funded by the "Strategic Priority Research Program-Climate Change: Carbon Budget and Relevant Issues" of the Chinese Academy of Sciences (XDA05130703) and the Chinese Academy of Sciences key deployment project (KZZD-EW-14). Thanks to Wang Yuandong, Wu Li, Di Xianghong, Yu Liangju, and Chang Yuanyong for the contributions they had made during the field surveys, and the processes of data downloading and processing.

\section{References}

Allersma E, Tilmans WMK (1993) Coastal conditions in West Africa: a review. Ocean Coast Manage 19(3):199-240

Alpar B (2009) Vulnerability of Turkish coast to accelerated sea-level rise. Geomorphology 107(1):58-63

Arkema KK, Guannel G, Verutes G et al (2013) Coastal habitats shield people and property from sea-level rise and storms. Nat Clim Change 3:913-918

Crowell M, Coulton K, Johnson C et al (2010) An estimate of the US population living in 100-year coastal flood hazard areas. J Coastal Res 26(2):201-211

Das S (2012) The role of natural ecosystems and socio-economic factors in the vulnerability of coastal villages to cyclone and storm surge. Nat Hazards 64(1):531-546 
Dwarakish GS, Vinay SA, Natesan U et al (2009) Coastal vulnerability assessment of the future sea level rise in Udupi coastal zone of Karnataka state, west coast of India. Ocean Coast Manage 52(9):467-478

Gesch DB (2009) Analysis of lidar elevation data for improved identification and delineation of lands vulnerable to sea-level rise. J Coast Res 53:49-58

Gornitz V (1991) Global coastal hazards from future sea level rise. Global Planet Change 3(4):379-398

Haer T, Kalnay E, Kearney M et al (2013) Relative sea-level rise and the conterminous United States: consequences of potential land inundation in terms of population at risk and GDP loss. Global Environ Change 23(6): 1627-1636

Jana A, Bhattacharya AK (2013) Assessment of coastal erosion vulnerability around Midnapur-Balasore coast, eastern India using integrated remote sensing and GIS techniques. J Indian Soc Remote 41(3):675-686

Kirwan ML, Megonigal JP (2013) Tidal wetland stability in the face of human impacts and sea-level rise. Nature 504(7478):53-60

Poulter B, Halpin PN (2008) Raster modelling of coastal flooding from sea-level rise. Int J Geogr Inf Sci 22(2):167-182

Reed DJ (1995) The response of coastal marshes to sea-level rise: survival or submergence? Earth Surf Proc Land 20(1):39-48

Saranathan E, Chandrasekaran R, Manicharaj DS et al (2011) Shoreline changes in Tharangampadi Village, Nagapattinam district, Tamil Nadu, India-A case study. J Indian Soc Remote 39(1):107-115

Thatcher CA, Brock JC, Pendleton EA (2013) Economic vulnerability to sea-level rise along the northern US gulf coast. J Coastal Res SI63:234-243

Torresan S, Critto A, Valle MD et al (2008) Assessing coastal vulnerability to climate change: comparing segmentation at global and regional scales. Sustain Sci 3(1):45-65

Torresan S, Critto A, Rizzi J et al (2012) Assessment of coastal vulnerability to climate change hazards at the regional scale: the case study of the North Adriatic Sea. Nat Hazard Earth Sys 12(7):2347-2368

Wang YD, Hou XY, Shi P et al (2013) Sensitivity analysis along the Bohai coast under the background of sea level rise. Sin Sci Geogr 33(12):1514-1523 (in Chinese)

Wu T, Hou XY, Xu XL (2014) Spatio-temporal characteristics of the mainland coastline utilization degree over the last 70 years in China. Ocean Coast Manage 98:150-157

Zhang CM, Liu QS, Liu GH et al (2014) Elevation quality evaluation of ASTERGDEM data in China's eastern region. J Geomat Sci Tech 31(1):67-72 (in Chinese) 